\title{
Relaciones entre Brasil y Argentina en la década del 80: de una cautelosa rivalidad a una competencia amistosa*
}

Los acontecimientos acaecidos desde 1979 han suavizado sostenidamente el tono que ha dominado por largo tiempo las relaciones brasileño-argentinas y han desarrollado un nivel de mutua confianza, así como mecanismos institucionales, que han logrado fomentar un mayor grado de cooperación. El entendimiento mutuo, establecido oficialmente durante una visita que marcó un hito en mayo de 1980, efectuada por el Presidente de Brasil, Jõao Figueiredo, al Presidente Jorge Videla en Buenos Aires, se atribuye más que nada a la percepción pragmática por parte de ambas capitales que las pequeñas rencillas acumuladas y sin resolver podrían transformarse en puntos de fricción innecesarios que socavarian acciones de mayor beneficio.

Este cambio de actitud ha demostrado ser perdurable al sobrevivir a varios gobiernos argentinos (tanto militares como civiles) y el conflicto de las Malvinas. El mismo Presidente Figueiredo asumió un rol de importancia al reestructurar la relación a partir de un interés personal en Argentina; al cabo de cuarenta años sin reuniones cumbre brasileño-argentinas, desde 1980 él se ha reunido con sus pares argentinos en cuatro oportunidades formales $y$ en una ocasión informal. El Presidente Electo Tancredo Neves se reunió con el Presidente Alfonsín en febrero de 1985 durante una jira en el exterior y se tomaron sustanciales acuerdos en asuntos claves**.

Entretanto, se ha dado inicio a una recomposición de la percepción mutua que es indispensable para seguir progresando. Las relaciones están siendo definidas cada vez más en términos de oportunidades que de controversias. Estas excelentes relaciones diplomáticas se están extendiendo hacia otras esferas de actividad. Ambos

*Este artículo aparecerá también en Política e Estratégia (São Paulo), 1985. El trabajo fue presentado en el Decimosegundo Congreso Internacional de LASA, Albuquerque, Nuevo México, abril de I9S5.

**Antes de asumir el mando, el Presidente Tancredo Neves falleció y lo sucedió Sarney. 
gobiernos están dispuestos a estar en desacuerdo en algunos aspectos de la política internacional, e incluso ir en pos de objetivos que difieren, sin que esto implique imputar a Ia otra parte motivos ulteriores cuando ésta no logra su propósito. Por otra parte, no se logrará erradicar totalmente el factor competitivo ni establecer una entente cordiale o hegemonía conjunta que actúe como móvil principal en la política exterior, ya sea en Brasilia o en Buenos Aires.

Se ha avanzado lo suficiente como para poder hacer una evaluación de la dinámica de la relación actual de política, economía y seguridad y anticipar, aunque sea presumiblemente, qué oportunidades, limitaciones y problemas yacen más adelante. Continuando por una senda positiva, las relaciones tendrán que ser manejadas conscientemente. Aún con los riesgos implícitos en predecir durante una situación de tal fluidez; es posible y útil hacer un esquema de las tendencias y factores que probablemente aflorarán e influirán tanto en la calidad como en la dirección que tomará la relación en lo que queda de esta década. Para enfocar hasta cierto punto la deliberación del rango de las probabilidades, el marco de tiempo se dividirá en corto plazo (1985-86) y mediano plazo (1987-1989), y se evaluarán los factores de continuidad y discontinuidad en cada período.

\section{RELAGIONES POLÍTIGAS: DINAMIGAS AGTUALES $\mathrm{Y}$ PERSPECTIVAS FUTURAs. DiNÁmiGas políticas actuales}

\section{Una historia ambivalente}

Las rivalidades $\mathrm{y}$ las sutiles tensiones entre los dos países se remon$\tan$ a la época colonial, aunque se aprecian elementos que indican cooperación en la mayoría de los períodos ${ }^{1}$. Para muchos argentinos, sin embargo, el punto que ocasiona mayor inquietud hacia Brasil en los últimos tiempos ha sido una cierta sensación de frustración al no poder lograr una clara primacía en Sudamérica, sitio al que estaría supuestamente predestinada. Las vacilaciones, las dificultades para lograr el desarrollo, y las divisiones internas de Argentina, que datan de 1930, contrastan con el sostenido crecimiento poblacional y económico de un Brasil más estable, de importancia mundial significativa, aunque con perturbaciones (ver tabla I para apreciar la creciente brecha entre los dos países de 1960 a 1980). EI sentido de superioridad racial y cultural que tiene la élite argentina hacia un Brasil de mucho mayor tamaño y con una gran mezcla

\footnotetext{
IElementos de cooperación y conflicto a través de la historia y hacia el futuro, analizadas por $\mathrm{H}$. Jaguaribe en "Brasil-Argentina: Breve Análisis de las Relaciones de Conflicto y Cooperación", Etudios Internacionales, Año xv, No 57 (enero-marzo 1982) pp. 9-27.
} 
Tabla 1

LA GREGIENTE BRECFA EN LA PRODUCGION DE BRASIL Y ARGENTINA, 1960-1980

\begin{tabular}{lcrr} 
& $\begin{array}{l}\text { Población } \\
\text { (millones) }\end{array}$ & & \\
& & & \\
& 1960 & 1970 & 1980 \\
\cline { 2 - 4 } & & & 119,0 \\
Brasil & 72,3 & 93,3 & 27,9 \\
Argentina & 20,3 & 23,2 & $4,3: 1$ \\
Razón & $3,6: 1$ & $4,0: 1$ &
\end{tabular}

- Producto Interno Bruto

(miles de millones de dólares 1982)

\begin{tabular}{|c|c|c|c|}
\hline & 1960 & 1970 & 1980 \\
\hline Brasil & $\$ 55,0$ & $\$ 100,0$ & $\$ 229,0$ \\
\hline Argentina & 32,7 & 49,0 & 62,6 \\
\hline \multirow[t]{3}{*}{ Razón } & $1,7: 1$ & $2,0: 1$ & $3,7: 1$ \\
\hline & \multicolumn{3}{|c|}{$\begin{array}{c}\text { Producto Interno per Cápita } \\
\text { (dólares 1982) }\end{array}$} \\
\hline & 1960 & 1970 & 1980 \\
\hline Brasil & $\$ 761$ & $\$ 1.078$ & $\$ 1.924$ \\
\hline Argentina & 1.586 & 2.065 & 2.240 \\
\hline Razón & $1: 2,1$ & $1: 1,9$ & $1: 1,2$ \\
\hline
\end{tabular}

Valor Agregado a la Economia por Manufacturas (miles de millones de dólares 1982)

\begin{tabular}{lrrr} 
& 1960 & 1970 & 1980 \\
\cline { 2 - 4 } Brasil & $\$ 13,7$ & $\$ 26,7$ & $\$ 63,0$ \\
Argentina & 8,0 & 13,2 & 15,5 \\
Razón & $1,7: 1$ & $2,0: 1$ & $4,1: 1$
\end{tabular}

Inversión Interna Bruta

(miles de millones de dólares 1982)

\begin{tabular}{lrrr} 
& 1960 & 1970 & 1980 \\
\cline { 2 - 4 } Brasil & $\$ 10,5$ & $\$ 22,7$ & $\$ 52,7$ \\
Argentina & 6,5 & 10,4 & 14,9 \\
Razón & $1,6: 1$ & $2,2: 1$ & $3,5: 1$
\end{tabular}

Exportación de Bienes y Servicios

(miles de millones de dólares 1982)

\begin{tabular}{rrr}
1960 & 1970 & 1980 \\
\hline 3,7 & $\$ \quad 6,5$ & $\$ 12,8$ \\
2,6 & 4,5 & 6,9 \\
$1,4: 1$ & $1,4: 1$ & $1,9: 1$
\end{tabular}

Fuente: Banco Interamericano de Desarrollo, Economic and Social Progress in Latin America, 1984 Report: Economic Integration (Washington, D. C.: BID, 1984). Apéndice Estadístico. 
racial, agravó aún más las disputas que se referían específicamente a diferendos típicos de comercio, régimen, frontera o esferas de influencia. El período de 1970 a 1976 estuvo particularmente plagado de problemas cuando el boom económico brasileño y la diplomacia de seguridad nacional del régimen militar coincidieron con un auge del nacionalismo en Argentina, que sospechaba intensamente de Brasil y tenía por objeto frenar el avance de su influencia ${ }^{2}$. La preocupación argentina aumentó considerablemente cuando Washington aparentemente seleccionó a Brasil como "país clave" en Sudamérica.

El afán argentino de calzar las relaciones internacionales en marcas geopolíticas "zero-sum", que prima especialmente en el pensamjento militar, ocasionó tensiones y colocó a Brasil en el rol de exitoso poder expansionista que presionaba a una débil e indecisa Argentina. El punto cúlmine de esta preocupación desde fines de los años 50 hasta la década de los años 70, se vio aún más intensificada por las ansiedades ocasionadas por las supuestas intenciones geopolíticas brasileñas que se vislumbraban de la lectura de trabajos geopolíticos exagerados del teórico Golbery do Couto e Silva respecto del rol de Ios militares brasileños y el gobierno, que se sumó al dramático aumento de la brecha en la producción económica entre los dos países, así como a una creciente presencia brasileña en Bolivia, Paraguay y Uruguay ${ }^{3}$.

Para Brasilia, Argentina también ha significado una preocupación, y en décadas recientes ha habido claras muestras de que existe un componente político en lo que de otra manera sería una política extranjera mayormente económica. Debido a que Brasil realiza más actividades de índole global y a la creciente disparidad de tamaño, Brasilia constituye más una preocupación para Buenos Aires que lo contrario. Sin embargo, Brasilia considera a Argentina como su más valioso compañero latinoamericano, así como uno de sus escasos socios en política exterior, con el cual sus relaciones deben ser cuidadosamente manejadas. En el peor de los estereotipos brasileños, Argentina aparece como un ejemplo negativo de inestabilidad política, arrogancia, indisciplina social, crueldad militar, debillidad organizacional, estancamiento económico y fuerza laboral inmanejable.

Dejando de lado el análisis estratégico de salón, Brasil ha tenido buen cuidado que sus iniciativas, como el Pacto de la Cuenca

${ }^{2}$ Stanley Hilton, "Las relaciones argentino-brasileñas: el punto de vista del Brasil", en Carlos J. Moneta, (ed.), Geopolitica y Politica del Poder en el Atlántico Sur (Buenos Aires: Pleamar, 1983), p. 29.

${ }^{3}$ Los matices de imágenes positivas y negativas de Argentina para con Brasil son exploradas por Carlos J. Moneta y Rolf Wichman, "Brazil and the South. ern Cone", en Wayne A. Selcher, ed., Brazil in the International System: The Rise of a Middle Power (Boulder, co: Westview Press, 1981), pp. 148-158. 
del Amazonas, no tomen un cariz antiargentino. Argentina tiene cierto valor como socio económico y es clave en las relaciones con Sudamérica, pero posee también el potencial adverso de haber jugado un rol político negativo. Por esta razón, el que las relaciones con Argentina sean buenas o aceptables es una prioridad urgente para Brasil, en parte para dejar lugar para otros problemas y socios de mayor importancia. Brasil no ha necesitado realmente el apoyo de Argentina para asuntos internacionales que tienen mayor urgencia, pero su apoyo siempre sería bienvenido.

\section{Un cambio de perspectiva}

El impetu hacia mejores relaciones se remonta a 1976, cuando el gobierno de Videla en Buenos Aires nombró a Oscar Camilión como Embajador ante Brasilia. Uno de los expertos argentinos de más renombre en el tema de Brasil, que luego ocupó el cargo de Ministro de Relaciones Exteriores, el Embajador Camilión trabajó intensamente para mejorar las relaciones entre los dos pafses y fomentar la cooperación. En Buenos Aires prevalecía cada vez más la idea de que compitiendo relegaría automáticamente a la Argentina al lugar del perdedor, en tanto que Brasil continuaba avanzando, dejando a su paso una brecha cada vez mayor.

El acuerdo mutuamente satisfactorio de la Represa de Itaipú en 1979 y la controversia respecto del aprovechamiento de los recursos hidráulicos por parte de ambos países, fueron las primeras consecuencias del estrechamiento de las relaciones, junto con la indemnización otorgada por Brasil a Argentina para compensar los daños menores resultantes del Ilenado de la represa. El conflicto de las Malvinas y sus consecuencias, al fin y al cabo, aceleraron la tendencia a la cooperación. De parte de Argentina, Ios motivos de quejas contra Estados Unidos y Europa Occidental dieron lugar a una "latinoamericanización" de la polftica exterior, en gran medida con el fin de reunirse y obtener apoyo en el asunto de las Malvinas. La postura de Brasil durante y después del conflicto fue, en general, bien recibida por los argentinos, a pesar de la relativa falta de entusiasmo por parte de Brasil y la forma en que salvaguardó sus relaciones con Gran Bretaña. La derrota de las Malvinas y la herida que sufrió la anti-imagen argentina ante el Occidente, dieron origen a un replanteamiento instrospectivo de las premisas y a la aparición de estudios que presentan nuevas interpretaciones y alternativas en cuanto al nuevo rol de Argentina en el mundo4. Las opiniones geopolíticas de los autores militares más orientadas hacia el

'Ver, por ejemplo, Carlos Pérez Llana, Reinserción argentina en el mundo: entre la politica exterior esquizofrénica y la politica exterior independiente. (Buenos Aires: E1 Gid Editor, 1983). 
conflicto que predominaban, están siendo ahora desafiados por análisis cooperativos e integracionistas de autores civiles, especialmente después de la inauguración, en diciembre de 1983, del gobierno democráticamente elegido de Alfonsin.

Posteriormente, el progreso obtenido en las negociaciones del Canal Beagle con Chile ha ayudado a aliviar la sensación de "encierro" de Argentina, ha debilitado al caballo de guerra geopolíti$c o$, y ha disminuido el grado de preocupación con respecto a un permanente foco de conflicto. Los militares argentinos, humillados nacional e internacionalmente, evaluaron sus relaciones con los ciriles. La correspondiente misión del Ministerio de Relaciones Exteriores en el desarrollo de políticas por seguir, incrementó el grado de compatibilidad entre Argentina $y$ Brasil. El aumento de la velocidad de la liberalización polf́tica de Brasil y lá aceptación gèneral de su nuevo rol como agente cooperativo en el Continente, hizo que el atractivo de Brasil como socio aumentara aún más.

Para Brasilia, Ia invasión argentina de las Malvinas hizo resurgir estereotipos que describen a Argentina como volátil y que destacan la necesidad de fomentar las relaciones internacionales cooperativas antes que las conflictivas en América del Sur. Los militares brasileños al principio miraron la invasión como una excusa hacia una expansión a gran escala y un mejoramiento de los equipos y las tropas, pero la derrota argentina determinó que los efectos reales en la política de defensa nacional fueran mucho más limitados. Hubo cada vez mayor consenso en el sentido que era poco probable que Argentina se embarcara en otra aventura militar. Algunos de los factores que contribuyeron a la derrota de Argentina, tales como el deficiente apoyo logístico, la débil coordinación entre las armas, la escasez de abastecimiento, constituyeron defectos que los planificadores brasileños pudieron apreciar en sus propias fuerzas armadas y empezaron a resolver sin necesidad de contar con una amenaza potencial especifica. Prevaleció la cómoda actitud por parte del Ministerio de Relaciones Exteriores en cuanto a que la diplomacia bien llevada y la mantención preventiva constituyen la mejor manera de asegurarse que, en el peor de los casos, Buenos Aires se convirtiera en un problema dada su conducta errática, y no en una amenaza de hostilidad armada dirigida contra Brasil, al menos en parte, al apreciar el aumento de preparación militar brasileñas.

En concordancia con la típica orientación brasileña en favor de la estabilidad en Sudamérica, a Brasil le conviene que Argentina no sea inestable por una parte, ni presa de un fervoroso $y$ arrasante

"Wayne A. Selcher, "Brazil's Foreign Policy: More Actors and Expanding Agendas", en Jennie K. LincoIn y Elizabeth G. Ferris, editores, The Dynamic of Latin American Foreign Policies: Challenges for the 1980s (Boulder, co: Westview Press, 1984), p. 31. 
nacionalismo, por la otra. Un mayor interés por la calidad de las relaciones fue el resultado que los alejó aún más del enfrentamiento y que les permita dirimir problemas "técnicamente" mucho antes que surjan o alcancen relevancia política. Brasil prefiere "despolitizar" la relación al máximo para poder dar énfasis a los asuntos económicos, como lo hace en otros casos.

Se pueden citar varios hitos en la nueva senda de la cooperación: la representación por parte de Brasil de los intereses diplomáticos de Argentina en Londres y sus esfuerzos para recomenzar las conversaciones respecto de las Malvinas, la liberación del montonero Mario Firmenich y su envío a Buenos Aires, las restricciones impuestas a los derechos de aterrizaje en Brasil de aviones británicos con destino a las Malvinas, y la concesión de un préstamo a corto plazo a Argentina para aliviar el acoso crediticio. Los dos gobiernos resolvieron en conjunto- los difíciles momentos posteriores a la torpe detención, por parte de unidades navales argentinas, del buque científico brasileño que transitaba por el Beagle con destino a la Antártida (enero de 1983), y que bien pudo haber creado un incidente de graves consecuencias cinco años antes. La construcción del primer nuevo puente para unir los dos países en más de 35 años se inició ese mismo mes. Los presidentes de Brasil y Argentina se unieron en una declaración latinoamericana cuatripartita con respecto a las tasas de interés y la deuda, y otorgaron un préstamo al gobierno elegido de Siles Suazo en Bolivia. Se firmaron a partir de 1980 nuevos tratados en diversas áreas de actividad. Como consecuencia de intermitentes consultas militares y civiles, y de cuatro reuniones cumbre para tratar diversos temas, nació un sistema de amplias consultas interministeriales entre ambos países en mayo de 1984.

\section{PaNorama político a FUTURo}

\section{Una situación de ambigüedad}

Lo que ha ocurrido ha sido denominado "salto conceptual", una nueva forma de enfocar la relación cualitativamente a nivel oficial. La supuesta, extensa y permanente rivalidad ha dado Iugar a una actitud más razonable, dispuesta a resolver problemas que afectan tanto a las relaciones bilaterales como al intercambio de ideas en el análisis de los asuntos regionales y mundiales. ${ }^{6}$. Lo que falta es lograr una aplicación práctica que sea concordante con la modificación que se aprecia en la percepción.

ๆfélix Peña, "Perspectivas de las relaciones entre la Argentina y el Brasil: algunos apuntes", Estudios Internacionales, Año xv, No 57 (enerommarzo, 1982), página 31. 
Ambos países han visto sus ambiciones restringidas en los últimos años y ninguno de ellos es expansivo en el grado de actividad internacional. Con el descenso que han experimentado las consideraciones de prestigio como móviles, la carrera para escalar posiciones en la esfera de influencia por parte de los tres estados "amortiguadores" ha disminuido. La mayoria de los argentinos, si bien de mala gana, han aceptado aparentemente que, en general, Brasil es económicamente más avanzado y continuará aventajando a su país. La idea que la cooperación con Brasil no conlleva necesariamente Ia desventaja para Argentina en calidad "socio menor", ha cundido. Brasil aparece cada vez más como fuente de oportunidades que como amenaza. Sin embargo, muchos argentinos no han renunciado a la fantasiosa idea que, de algún modo, su país puede mantener una especie de "paridad" con Brasil en cuanto a sus posibilidades. Tampoco se han abandonado completamente los estereotipos negativos por parte de ninguno de los dos lados.

No hay conflictos de importancia entre los dos estados en este momento, pero tampoco se ha elevado el nivel de mutua conciencia como para que exista un grado más alto de cooperación que una evaluación objetiva encontraría factible. Ninguno de los dos países desea ser guiado por el otro, pero Argentina tendrá que tomar más seriamente en cuenta las opiniones brasileñas a medida que pasa el tiempo. Ambos países miran hacia adentro o hacia otros lugares primero, en lugar de hacia el otro para satisfacer sus necesidades, tanto a nivel del gobierno como del sector privado. (Ver tabla 2 sobre percepción mutua). El fracaso de la organización de la Guenca del Plata, que reunía a cinco miembros, se debe a esta propensión, tal como es el caso de los tratados de cooperación de largo alcance que todavía cuentan con escaso impulso. El carácter tentativo de Ias instituciones políticas emergentes y la reestructuración económica nacional exigirán mucha atención inmediata de parte de los gobiernos y hacen que sea poco probable que se lleven a cabo medidas novedosas a corto plazo, que se aparten de una mera intensificación del comercio.

Un aspecto fundamental en el futuro de las relaciones es la reciente aceptación por parte del gobierno brasileño de la importancia que reviste el hecho que el país es el poder predominante en el 'Continente y que, lentamente, está expandiendo la participación. tangible con respecto a lo que sucede en el resto del Continente. La forma que tomará esta participación no está aún clara, pero será gradual (a menos que haya un transtorno de grandes proporciones en algún país yecino) y no es probable que sea hegemónico. Empezando con el ágil intercambio de visitas presidenciales y firmas de tratados del gobierno de Figueiredo, incluyendo el nombramiento como Secretario General de la oEA del diplomático brasileño Jõao Clemente Baena Soares, y extendiéndose al gobierno de Neves, Bra- 


\title{
PREFERENGIAS PUBLICAS DE COOPERACION INTERNACIONAL EN ARGENTINA Y BRASIL, MAYO DE 1981
}

\begin{abstract}
Pregunta: "Nuestro país, como nación, tiene ciertos intereses. ¿Con qué paises del mundo deberíamos trabajar más estrechamente para avanzar $y$ mejorar a nosotros mismos?
\end{abstract}

\section{Orden de Preferencia de Público Argentino}

Estados Unidos
Japón
Alemania Occidental
Pafses Arabes
URss
Reino Unido
BrasIL
Venezuela
Francia
México
Cuba

\section{Orden de Preferencia de Público Brasileño}

Fuente: Foreign Opinion Note del 6 de junio de 1981, Office of Research, U.s. Information Agency, Washington, D. C.

Observaciones: Esta muestra de opinión pública realizada antes del conflicto de las Malvinas, a pedido de Gallun Sud nor la USIA, proporciona una visión especial de encuesta con respecto a las imágenes mutuas de Argentina y Brasil, al menos en las áreas urbanas. Es interesante notar que, proporcionalmente, tres veces más argentinos consideren a Brasil como socio valioso para el progreso que viceversa. En el caso de ambos hubo una mayor preferencia, leve, por cooperar con la uRss que con el vecino. Sin embargo ambos percibieron niveles semejantes para Francia y el Reino Unido como socios. El mayor aislamiento relativo de opinión en Brasil, expresado por porcentajes menores de deseos de cooperar con cualquier socio, es quizá un reflejo de la mentalidad de "país grande".

En la misma encuesta, cuando se preguntó cuáles eran los países más conflictivos en Sudamérica, sólo $6 \%$ de los argentinos encuestados nombró a Brasil primero, mientras que el $27 \%$ nombró a Chile, y el $9 \%$ nombró a la misma Argentina. De los brasileños encuestados, $11 \%$ nombró a Argentina en primer Iugar, seguido por Perú, 10\%. Las estadísticas no muestran ambientes negativos de opinión pública mutua. 
sil está reafirmando una identidad latinoamericana tanto de un modo práctico, como retórico. Una de sus premisas establece que se debe desviar la atención de las disputas territoriales y concentrarse en asuntos de desarrollo. Si el gobierno cree que las posibilidades de tener éxito son altas, el interés de Brasil se manifestará en una acción cauta, modesta y casi renuente. No es probable que actúe precipitada o aventuradamente. Brasil devengará ganancias de una América del Sur cooperadora y económicamente saludable, para lo cual las relaciones cooperativas con Argentina constituyen un prerrequisito.

\section{Condiciones politicas a corto plazo (1985-1986)}

El proceso de democratización reciente en ambos países ha constituido un elemento crucial para el entendimiento político entre ambas potencias. Con la asunción de Raúl Alfonsín al poder en Buenos Aires y con un gobierno civil en Brasilia, es muy improbable que la aproximación entre los dos países sufra un revés. Cabe es. perar un.alto nivel de cordialidad $y$ entusiasmo a nivel retórico dada la compatibilidad ideológica que corresponde a la "redemocratización del Continente". El círculo de consejeros de Tancredo Neves incluye a muchos que se inclinan por una política exterior independiente en favor de la cooperación en América Latina. (Uno de los persistentes impedimentos durante las tres últimas décadas lo constituyó precisamente la falta de esa "sincronización política" con respecto a metas nacionales y visión global). Argentina puede apoyar de un modo más retórico los derechos humanos y el establecimiento de la democracia en otros países que no sean Brasil como elemento clave para su reintegración a América Latina. Sin embargo, algunos discursos brasileños levemente alusivos al tema, junto con alguna ayuda, serían algo constructivo y afirmaría la posición de Brasil en la tendencia que se advierte en el Continente, sin que se requiera, necesariamente, una contribución de gran envergadura.

Habrá pocos efectos directos entre los dos países durante el proceso de redemocratización, incluyendo el trato con los militares, porque cada proceso es autónomo. No obstante se podrá apreciar el poder del ejemplo, de estímulo o de desánimo. Los intercambios congresionales e intelectuales con respecto al tema de la democracia y las relàciones conjuntas experimentarán una recuperación. Gabe esperar también un aumento en los intercambios culturales y noticiosos, que ayudará a crear una imagen recíproca más positiva. Antiguos rencores y desconf:anzas tenderán a disminuir lentamente y emergerá un sentido de competencia amistosa (en contraste con la cauta rivalidad de antaño). Brasil seguirá siendo objetivo potencial del descontento argentino más que viceversa. 
El éxito sostenido de estas dos democracias y la fuerza de su relación constituirán un ejemplo que presionará indudablemente al gobierno de Pinochet en Chile y fomentará la liberalización de Uruguay. Sus efectos en una más tumultuosa Bolivia y en un Paraguay más estancado, son más inciertos. El efecto neto, más indirecto que directo, sería hacia una mayor moderación y evolución hacia el cambio en el Cono Sur.

Tanto Argentina como Brasil desempeñarán roles de importancia al conceptualizar y poner en práctica un entendimiento coordinado de las posibilidades existentes para la cooperación económica en América Latina. La resolución del problema de la deuda será el ftem prioritario en la agenda de cada cual, con una alta probabilidad de acercamiento "político". Las posibilida'des para ejercer presión sostenida o simultánea sobre los acreedores con el fin de conseguir opciones como la estabilización de las tasas de interés, techo en las tasas de interés, o pagos limitados a un cierto porcentaje de las ganancias por exportaciones, son buenas, en beneficio de las obligaciones sociales y la preservación de las frágiles democracias. Lo más probable es que haya al principio una declaración política común en un espíritu de compromiso (y también de advertencia) para crear las condiciones sistemáticas para efectuar negociaciones separadas, pero más favorables. También cabe la posibilidad que se continúe por la senda de alternar la obtención de mejores condiciones de pago de los acreedores, basada en las concesiones conseguidas antes por el otro lado. (México es el tercer socio de importancia en este juego).

La formación de un "cartel de deudores" más radical para crear un frente unido más insistente y más amplio aparece probable sólo como último recurso si las condiciones de pago se hacen excesivamente pesadas. Brasil está mucho menos ansioso que Argentina por lograr una solución multilateral, en parte porque percibe que Argentina es mucho menos responsable para efectuar ajustes a la deuda. Un grave empeoramiento de la capacidad de América Latina para pagar, que ocasione una importante constricción del "espacio económico para respirar" y sus consecuencias socio-políticas, bien podría sobrepasar la renuencia de Brasil, dada su propia situación, su creciente identificación con América Latina, y la implicancia de su seguridad política y económica, presente y futura, en la estabilidad y el crecimiento de la región. Si los acreedores se negaran a reconocer en el terreno práctico la naturaleza impagable de la deu$\mathrm{da}$, en cualquier circunstancia, podría hacer que la amenaza de parámetros y descargar presiones en última instancia pareciera menos dañina para las dos economías nacionales cooperadoras que continuar con un flujo de capital hacia el exterior, que atenta contra su desarrollo y constriñe la política económica creando desbarajuste social. Brasil y Argentina, en la práctica, habrian obtenido 
entonces un tratamiento equivalente ante la postura más o menos unida que han adoptado los acreedores hacia cada uno de ellos en forma separada7.

Brasil continuará reacio a poner a su relación con Argentina la corona de "relación especial" para así permanecer, al menos nominalmente, imparcial en el manejo de sus asuntos continentales. Tendrán que pasar años de mayor calma en Buenos Aires, sin embargo, antes que Brasil considere a Argentina políticamente estable y económicamente dinámica como para comprometerse a efectuar proyectos económicos bilaterales de mayor envergadura, dadas sus inquietudes en cuanto a su capacidad, tanto para contribuir, como para cumplir.

\section{Crondiciones politicas en el mediano plazo (1987-1988)}

En el corto plazo se apreciarán más instancias de planificación y conceptualización que logros reales, pero el éxito depende, a fin de cuentas, de una serie de factores políticos que se pueden identificar desde ya. Entre los de mayor importancia se cuenta el éxito de las dos nuevas democracias y la institucionalización de la cooperación. Los factores extranjeros más determinantes en el periodo comprendido de 1987 a 1989 se referirian a tendencias en América Latina, particularmente en Sudamérica. El sendero que tome el asiento de la deuda constituirá probablemente el factor externo único de mayor trascendencia, porque afecta a muchas otras variables económicas y políticas. La mayorla de los acontecimientos políticos que ocurran fuera de América Latina tendrán mucho menor impacto, a menos que consigan desviar la atención del Brasil hacia otro lugar, - lleven a un escalamiento de las tensiones mundiales. Por otra parte, la calidad de la relación puede tener efectos de gran importancia en los niveles de tensión en América del Sur, especialmente en el Cono Sur. El éxito en lograr la cooperación fortalecerá un poco el rol de ambos países en el ámbito mundial (especialmente el de Brasil) tanto en imagen como en capacidad, dará apoyo a sus negociaciones con terceros, y dificultará que terceras partes puedan colocar al uno en contra del otro, ni siquiera en forma implícita.

Como ejercicio teórico, las posibles tendencias políticas podrían dividirse entre aquellas que tratan de fortalecer los lazos y aquellas que tienden a debilitarlos, “ordenados, a grandes"rasgos, en grado descendente de probabilidad dentro de una magnitud de importancia.

Ver comentarios del senador PMDB brasileño, Severo Gomes (SP), ex Ministro de Economia y Comercio bajo el gobierno de Geisel, en Mónica Hirst, "Las relaciones Argentina-Brasil frente a la crisis", América Latina/Internacional (glacso, Programa Buenos Aires), Vol. 1, No 2 (octubre-diciembre 1984), p. 46. 
POSIBLES TENDENCIAS POLITICAS QUE FORTALECERIAN LOS LAZOS DE UNION

Mayor impacto

1. Gobierno civil continuado y estable en ambos paises, con políticas de desarrollo y miras al exterior.

2. Desarrollo continuado del concepto socio-económico, de seguridad nacional, en contraste con el concepto de defensa nacional.

3. Acuerdo de la disputa territorial de Argentina con Ghile y por lo menos una atenuación de la controversia de las Malvinas.

4. Alivio de las condiciones de pago de la deuda para ambos países, pero especialmente para Argentina.

5. Lazos más profundos del sector privado.

6. Progreso sostenido y aceptable de los proyectos conjuntos, tales como los recursos hidráulicos de la cuenca del Río de la Plata.

7. Deterioro de las condiciones del pago de la deuda, al punto que la única salida parezca ser una postura de enfrentamiento a los acreedores y un esfuerzo económico conjunto parece ser la única salida.

\section{Menor impacto}

1. Estabilidad en los países vecinos del Cono Sur.

2. Continuado énfasis en el concepto argentino de "latinoamericanización", que ha dado hasta ahora escasos beneficios aparte de la conexión brasileña.

3. Continuado dinamismo del diálogo intralatinoamericano en favor de la cooperación económica, como sería a través del Sistema Económico Latinoamericano (SELA), y la Asociación Latinoamericana de Integración (ALADI), que ambos países apoyan en principio.

POSIBLES TENDENCIAS POLITICAS QUE DEBILITARIAN EL LAZO DE UNION

\section{Mayor impacto}

I. Inestabilidad argentina o vuelta al poder por parte de los peronistas o sectores militares de derecha en el país.

2. Crecimiento sostenido de Brasil, concomitante con estancamiento o regresión por parte de Argentina, que destruya ostensible- 
mente la noción de "paridad" que todavía mantienen algunos nacionalistas argentinos.

3. Resurgimiento de corrientes geopolíticas en cualquiera de los países, pero especialmente en Argentina.

4. Empeoramiento de la situación concerniente al pago de la deuda externa para cualquiera de los dos países, pero sólo si logra alcanzar un grado que domine la política exterior y que invalide opciones nuevas, como la acción conjunta ante los acreedores.

5. Una intensa preferencia por parte de Estados Unidos hacia cualquiera de los dos países, pero especialmente hacia Brasil y particularmente en asuntos referentes a tecnología nuclear o militar.

6. Obsesión por parte de Argentina con la controversia de las Malvinas o cuestiones de frontera con Ghile.

7. Surgimiento de un alto grado de influencia brasileña en el Continente, especialmente en el Cono Sur y si se lleva a cabo, en forma aparatosa (Paraguay sería el candidato más probable).

8. El nivel de incertidumbre política en Brasil alcance niveles tan altos como para dar lugar a una introversión nacional y causar ansiedad respecto de la distribución interna del poder.

\section{Menor impacto}

1. Exigencia por parte de Argentina en el sentido de efectuar una revisión sustancial del acuerdo tripartito de Itaipú-Corpus.

2. Altas expectativas por parte de Argentina en el sentido de obtener apoyo brasileño para tomar posiciones altamente definidas en materias que Brasil preferiría enfrentar en forma moderada o retraída, como por ejemplo, la deuda, las Malvinas, apoyo a Ia democracia, o intervención militar norteamericana en América Central.

\section{RELACIONES EGONÓMICAS: DINÁMIGA ACTUAL $Y$ PERSPECTIVAS FUTURAS}

Ahora que se han resuelto diferencias politicas pendientes, la medida de la calidad de las. relaciones la darán los resultados económicos, especialmente en el comercio, la tecnología y posiblemente, en acciones que refuercen mutuamente la posición ante la deuda externa. Problemas estructurales persistentes han impedido mayor progreso inmediato, pero hay importantes acuerdos recientes a nivel de gobierno que parecen indicar un vuelco inminente que nos aleja de lo que ha sido hasta este momento un caso de desatención co- 
ESTUDIOS INTERNACIONALES

\section{Tabla 3}

VALOR ABSOLUTO DE LA PRODUCCION COMERGIAL

BRASILENTO.ARGENTINO 1973-83

(Expresado en millones de us dólares actuales)

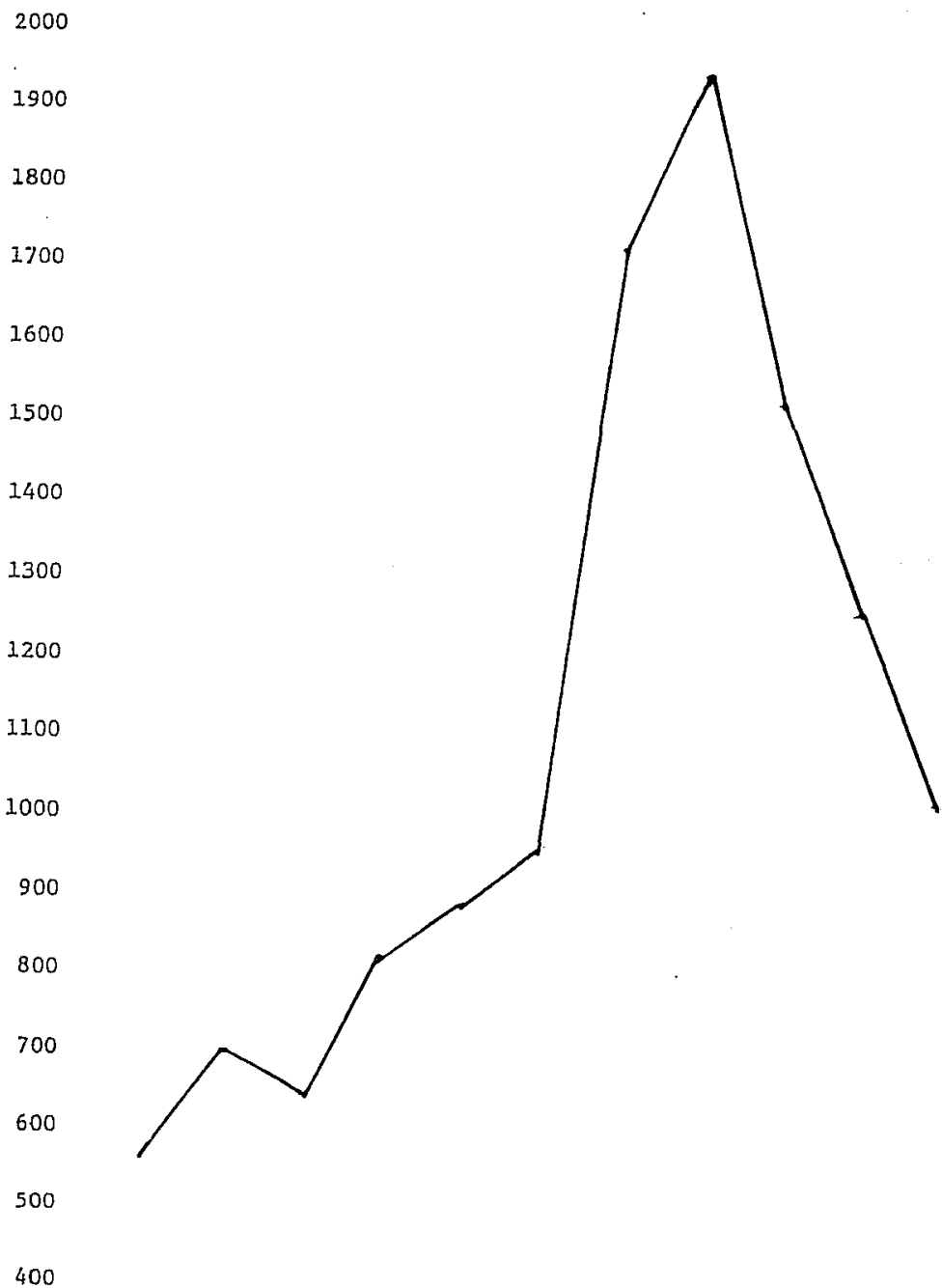

$\begin{array}{llllllllllll}0 & 73 & 74 & 75 & 76 & 77 & 78 & 79 & 80 & 81 & 82 & 83\end{array}$

Fuente: Libro anual de Direction of Trade, Fondo Monetario Internacional, 1980 y 1984. (Sacado de los totales para Brasil).

$\left[\begin{array}{lll}2 & 8 & 4\end{array}\right]$ 
mercial mutua y nos acerca a la interdependencia. A nivel conceptual, la cooperación económica y sus limitaciones han sido extensamente analizadas gracias a la notable proliferación de conferencias tanto del sector público como privado desde fines de 1982 en adelante, y gracias también a la labor efectuada por una comisión binacional.

\section{Comercio}

El intercambio comercial entre Brasil y Argentina ha sido uno de los mayores entre países en vías de desarrollo no-exportadores de petróleo. Ha sido irregular durante la última década (ver Tabla 3) debido a los bajos niveles de atención mutua y políticas aplicadas al comercio dominadas por consideraciones al corto plazo. Si bien alcanzaba a menos de mil miliones de dólares en total hasta 1978, se disparó hasta llegar a cerca de dos mil millones de dólares en 1980, debido en gran parte a la respuesta de Brasil a la política fomentada por el Ministro de Economía argentino, José Martínez de Hoz, en favor de la importación y del libre comercio, que más tarde fuera desacreditada. Guando se retiró la tasa de incentivo, la recesión y la restricción a las importaciones en ambos países, junto con el conflicto de las Malvinas, redujeron el comercio en cerca de la mitad en tres años. La exportación de bienes de capital por parte de Brasil a Argentina se vio especialmente afectada. Los exportadores brasileños se pusieron aprensivos en cuanto a venderle a Argentina debido a problemas de pago. En su momento cúlmine, el comercio estaba altamente diversificado, y Brasil embarcaba más de 1.300 tipos de ítemes a Argentina, en tanto que Argentina enviaba sobre 800 tipos de ítemes a Brasil. En las exportaciones argentinas domina típicamente la materia prima, mientras que en las de Brasil predominan los bienes manufacturados. A partir de 1980 ha prevalecido la situación de una persistente inclinación de la balanza en favor de Brasil, lo que le significa a Argentina un gasto muy alto de moneda dura y ocasiona quejas de tipo crónico.

Las dos economías, primera y tercera en tamaño dentro de América Latina, no han demostrado una gran tendencia al comercio entre ellas, a pesar de su proximidad. Tampoco ha habido propensión al aumento del intercambio comercial como reflejo del lugar que ocupa cualquiera de los socios en el ámbito global. (Tabla 4). Aún en su mal Iucido intento de comercio con el Tercer Mundo realizado hasta 1981, Brasil tuvo más exito en otras partes; a partir de 1982 ha concertado la mayor parte de sus esfuerzos de promoción en mercados occidentales y del Este asiático, aunque especialmente, en Estados Unidos. La característica más sobresaliente del comercio argentino durante la década pasada ha sido el aumento de ventas efectuadas a la URSs, con la ayuda parcial que proporcionó 
Tabla 4

LA IMPORTANGTA RELATIVA DEL COMERGIO BRASULENO-ARGENTINO EN RELACION AL COMERCIO TOTAL DE GADA SOCIO, 1973-1983

(Expresada en porcentajes)

\begin{tabular}{lllllllllll}
1973 & 1974 & 1975 & 1976 & 1977 & 1978 & 1979 & 1980 & 1981 & 1982 & 1983 \\
\hline
\end{tabular}

Para Argentiná

Exportaciones a Brasil

Total exportaciones

Importaciones de Brasil

Total importaciones

$\begin{array}{lllllllllll}9,5 \% & 8,7 \% & 7,2 \% & 10,8 \% & 8,2 \% & 9,0 \% & 11,3 \% & 9,5 \% & 6,5 \% & 7,4 \% & 4,2 \% \\ 9,2 & 8,2 & 9,1 & 12,2 & 4,2 & 3,7 & 9,8 & 2,4 & 3,6 & 7,4 & 8,3\end{array}$

PARA BRAsIL:

Exportaciones a Argentina Total exportaciones

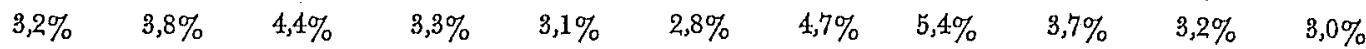

Importaciones de Argentina

Total importaciones

2,7

1,9

3,4

3,8

3,9

5,0

3,4

2,6

2,8

2,2

Fuente: Libros Anuales de Direction of Trade, Fondo Monetario Internacional, 1980 y 1984. 
el embargo de granos aplicado por Estados Unidos a Moscú. Argentina también realiza proporcionalmente más intercambio de comercio con América Latina que Brasil.

Argentina constituyó el noveno mercado de mayor importancia para Brasil tanto en 1973 como en 1983, mientras que Brasil ocupó el octavo lugar, después de haber estado en el segundo, entre los mercados de exportación de Argentina ${ }^{8}$. Inmediatamente después del conflicto de las Malvinas, los altos mandos argentinos hablaron de sustituir metódicamente las importaciones desde Europa Occidental con productos provenientes de Brasil, pero con el restablecimiento de las relaciones con Europa la idea fue abandonada y no tuvo un impacto real.

Brasil no ha tenido problemas para encontrar productos que comprar en grandes cantidades de Argentina, aunque no correspondiera más que a una inspiración política y quizá fuera inicialmente un alejamiento antieconómico de las fuentes proveedoras tradicionales. El abastecimiento interno y las políticas de sustitución de las importaciones por parte de Brasil pueden agravar aún más el problema a medida que su economía sigue reestructurándose. Brasil prefiere, por ejemplo, el trigo canadiense o norteamericano al argentino, tanto en tipo como en financiamiento, y está progresando en la producción de fruta típica de zonas templadas en su propio territorio. Argentina no vende ninguna materia prima industrial de importancia que Brasil necesite; $y$, aunque se ha hablado de ventas de gas natural, recientes descubrimientos dentro de Brasil pueden anular incluso eso. Incluso en el último ítem de comercio prometedor, la energía eléctrica, es Brasil el que le vende a Argentina más que al contrario.

La posible sustitución más obvia es el trigo, en el cual Brasil puede sustituir adquisiciones de apreciable monto de Estados Unidos y Canadá (donde goza de superávit en la balanza comercial) para fomentar un comercio equilibrado con Argentina a un nivel más alto. El incentivo argentino hacia un comercio equilibrado en este caso, no obstante, es menor, porque ha estado obteniendo altos excedentes en dólares con sus ventas de trigo a la urss. Por otra parte, una sustitución en la adquisición de trigo de la Unión Soviética hacia Estados Unidos haría que el mercado brasileño cobrara atractivo para Argentina.

La economía brasileña, aparte de su mayor tamaño y diversificación, es menos abierta que la argentina, mucho más estatizada y dirigida, más dinámica y menos dependiente del comercio exterior. Las quejas de los industriales argentinos contra los subsidios brasileños para productos manufacturados son bien conocidos en re-

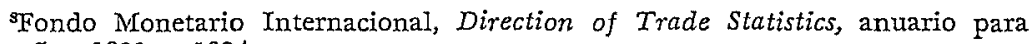
los años 1980 y 1984 . 
uniones comerciales y hacen surgir amenazas de proteccionismo. Represalias y contrarrepresalias ocurrían con frecuencia a principios de la década de los 80 . Los productos manufacturados argentinos están afectos a un mercado interno restringido $y$ se desempeñan menos bien que los brasileños en el mercado extranjero en general, porque tienen desventajas en cuanto a calidad, precio, financiamiento, mercado y entrega. El reciente esfuerzo por parte de ambos países para promover las exportaciones y frenar las importaciones sólo empeorará la situación, a menos que se firmen acuerdos regulares con el fin de establecer líneas de crédito para centros de distribución y comercio compensado de tipo recíproco. En este momento, el comercio compensado es visto mayormente como una medida de emergencia, pero Brasil se dedicará a promoverlo intensamente si los problemas de flujo de caja se tornan más severos para él mismo o para un importante socio comercial, como lo sería un país en vías de desarrollo del cual no pudiera esperar obtener un superávit en moneda dura.

La lentitud para resolver problemas comerciales como éste es una muestra de los obstáculos estructurales que existen para establecer una cooperación económica más amplia, tal como lo serían acuerdos de complementaridad industrial, y mucho menos, lograr la "integración de las economías" a la que a veces se refieren en discursos optimistas. El rango de complementaridad puede ser amplio, pero cada área tiene poco arrastre en relación a las obligaciones en otras partes. La mayoría de los factores de ventaja relativa tiende a favorecer a Brasil. La resolución de los asuntos de comercio bilateral más importantes tendrá que llevarse a cabo antes que se puedan establecer acuerdos de complementaridad industrial o comercio multilateral en el Cono Sur, que requieren de una interacción coordinada más estrecha.

\section{Proyectos conjuntos y cooperación tecnológica}

Una cantidad reducida de actividad en inversiones conjuntas o servicios se puede esperar que ocurra sólo esporádicamente, porque ambos países continuarán orientados hacia las fuentes tradicionales de inversión y tecnología para mantener las cosas como están. Ninguno de los dos países está interesado mayormente en las inversiones extranjeras; la especulación de bienes raíces se ha dado con mayor frecuencia entre los dos. Tampoco se han mostrado muy receptivos a los contratos de servicios entre ambos países. Aún hay poca cooperación científica, aunque ambos podrían ganar en la investigación y el desarrollo conjunto.

Hasta la fecha parece que la mayoría, quizá casi toda, la cooperación industrial entre ambos países ocurre como resultado de la 
actividad realizada por empresas multinacionales. Sin embargo, un fondo común de recursos o la complementaridad industrial bien podrían utilizarse en proyectos hidroeléctricos (a unos años vista dada la demanda reducida), tecnología de combustible b:omasa, crianza de ganado, minería, energía, ingeniería, petroquímica, acero, repuestos automotrices, herramientas de maquinaria, aviación, computación, microelectrónica y ciencia nuclear. Los trabajos conjuntos en investigación y desarrollo o proyectos de servicio darán origen a escalas de producción más económicas y lazos de un:ón más profundos que aquellos que resultarían del simple intercambio comercial. Debido a que la tecnología industrial, la infraestructura civil, y los contratos de consultoría de ambos países están prioritariamente en América Latina, y la mayoría en Sudamérica, tanto la cooperación como la competencia pueden llevarse a cabo en terceros países.

\section{Perspectivas económicas futuras}

\section{Condiciones económicas en el corto plazo (1985-86)}

Se han identificado las complementaridades, y los mecanismos para promover y monitorear el intercambio han sido establecidos hace poco tiempo. Éstos deben ser fomentados intensamente, porque para romper los esquemas del pasado ambos países necesitan concitar. Ia atención del otro en forma más prolongada y ofrecer más. La relación debe tener un grado de reforzamiento proveniente de amplios proyectos para que sobreviva y quizás alcanzar un grado de obvia interdependencia que no existe en este momento. Las preferencias mutuas y la recanalización de las obligaciones de otras partes hacia esta unión será indispensable y constituirá un indicador de la seriedad del compromiso. Las ventajas seguirán favoreciendo a Brasil en la mayoría de los sectores y harán necesario que se efectúen los ajustes pertinentes para asegurar la participación argentina en condiciones equitativas. (Brasil tiene ahora un $40 \%$ de todo el PIB de América Latina, medido con el valor agregado, mientras que Argentina no tiene más que un $9 \%)^{9}$.

La iniciativa para producir un cambio provino en mayor medida del Brasil, diseñando sus modelos y buscando intensificar relaciones de todo tipo con socios claves del Tercer Mundo. y estableciendo luego comisiones binacionales para hacerlas realidad. Tanto Brasil como Argentina se han rendido ante la imposibilidad de lo-

${ }^{\circ}$ Economic and Social Progress in Latin America, 1984 Report: Economic Integration (Washington, D. G,: Banco Interamericano de Desarrollo, 1984), p. 424. 
grar una integración regional en América Latina y ahora prefieren establecer lazos de acuerdos bilaterales antes que los vastos acuerdos multilaterales. Cada uno puede ser potencialmente un socio importante del otro. La sensibilidad mutua y los deseos de lograr una relación más amplia están ahora a un alto nivel, pero los beneficios tangibles deberán fluir en los próximos años, porque las economias necesitan retribuciones a corto plazo para fomentar la continuación del compromiso. Los altos mandos en ambos países se han referido (quizás en forma demasiado optimista) a la posibilidad de alcanzar un nivel de intercambio equilibrado de 4 a. 5 mil millones de dólares dentro de algunos años, más del doble del máximo alcanzado durante 1980. Los compromisos a nivel de gobier. no seguirán siendo de crucial importancia.

\section{Ciondiciones económicas a mediano plazo (1987-89)}

El éxito en fomentar la cooperación tendrá efectos positivos para Bolivia, Ghile, Paraguay y Uruguay, porque estos cuatro países forman un bloque comercial intrarregional con Argentina y Brasil desde que Chile se retiró del Grupo Andino y Bolivia volcó su énfasis comercial hacia el sur. Con el estancamiento de las negociaciones comerciales regionales, los bloques subregionales basados en esquemas comerciales actuales, tal como este grupo del Cono Sur, representan alternativas más viables y prácticas para la liberalización del comercio ${ }^{10}$. Argentina comercia proporcionalmente en mayor cantidad con esta subregión de lo que lo hace Brasil, pero este último espera que las innovaciones comerciales con Argentina se transformen en un modelo o un núcleo para la expansión de acuerdos subregionales, o incluso, de acuerdos a mayor escala. Uruguay es el primer socio más probable, seguido de Paraguay. Deberán cuidarse los intereses de los países más pequeños. Si los efectos de las iniciativas conjuntas de los dos gigantes afectaran a muy corto plazo a terceras partes, los países más pequeños podrían reaccionar negativamente, en forma muy parecida a la manera en que el comercio entre Brasil y Argentina, hace un tiempo, estimuló la formación del Grupo Andino.

Una vez más, las posibles tendencias se pueden dividir entre aquellas que refuerzan y aquellas que debilitan la relación, ordenadas en orden de probabilidad descendente dentro de un margen de importancia.

10" "Intra-Regional Trade", Economic and Social Progress in Latin America, 1984 Report: Economic Integration (Washington, D. C.: Banco Interamericano de Desarrollo, 1984), pp. 112.116. 
TENDENCIAS ECONOMICAS PROBABLES QUE REFORZARIAN LOS LAZOS

$$
\text { Mayor impacto }
$$

1. Exito en el comercio de compensación o crédito recíproco en la contabilidad de un centro de abastecimiento para disminuir los problemas de flujo de caja.

2. Redirección del flujo comercial y concesión de preferencias mutuas.

3. Alivio de las condiciones del pago de la deuda en un grado que reduzca las restricciones a la importación.

4. Recuperación económica de ambos países, especialmente Argentina.

5. Cooperación bilateral o subregional en asuntos de energía, especialmente el gas natural y la energía hidroeléctrica.

6. Recesión económica en un grado que impulse el comercio de compensación, que lleve a compartir recursos y logre la sustitución conjunta de las importaciones.

7. Cooperación entre las ramas de las empresas multinacionales ubicadas en ambos países.

8. Gran rebalse de los esfuerzos cooperativos hacia el sector privado.

9. Efectiva integración industrial en áreas tales como maquinaria, herramientas y petroquímica.

$$
\text { Menor impacto }
$$

1. Espiritu catalítico de integración económica a través de ALADI o SELA (aunque se lograría más en este caso a través de medios estrictamente bilaterales o quizá subregionales).

2. Intercambio de cientistas naturales y sociales con proyectos de investigación conjunta.

3. Coordinación de mercado o mercadeo (por ejemplo, semillas de soya y carne de vacuno) en el Cono Sur antes que en Europa Occidental y Estados Unidos.

4. Habilidad e interés brasileño para invertir en el exterior.

5. Revitalización del grupo de la Cuenca del Río de la Plata.

6. Proyectos de servicios conjuntos y cooperación comercial en terceros países, quizá a través de compañías comerciales binacionales. 
PROBABLES TENDENCIAS ECONOMICAS QUE DEBILITARIAN EL LAZO

Mayor impacto

1. Economías estancadas o recesivas en cualquiera de los dos países.

2. Continuo énfasis en el comercio con la Unión Soviética por parte de Argentina, o en los mercados occidentales y asiáticos por parte de Brasil.

3. Condiciones más pesadas en el pago de la deuda.

4. Brecha más grande en la competitividad económica que provocaría el proteccionismo argentino contra Brasil y produciría pérdidas para Argentina en terceros mercados.

5. Fuerte vuelco brasileño hacia el mercado interno, abastecimiento interno y sustitución de las importaciones, especialmente en los rubros de alimentos o gas natural.

\section{RELACIONES DE SEGURIDAD: DINÁMICA ACTUAL Y PERSPEGTIVAS FUTURAS}

\section{DINAMIGAS AGTUALES DE SEGURIDAD}

\section{Nivel convencional}

La mutua cautela entre los dos países ha sido tradicionalmente más fuerte en las instituciones militares. Los asuntos problemáticos que se relacionan con la seguridad han disminuido considerablemente, pero no desaparecido del todo, al mejorar las relaciones políticas y al volcarse la preocupación de una defensa territorial hacia un concepto mayormente socioeconómico de seguridad nacional. (La doctrina brasileña ha enfatizado este punto desde hace algún tiempo, y el gobierno de Alfonsín representó un cambio radical para Argentina en este aspecto). De hecho, durante fines de la década del 70, Brasil se transformó en el distante tercer foco de preocupación en cuanto a seguridad para Argentina, después de Gran Bretaña (con las Malvinas) y Chile. En varias ocasiones, especialmente durante la controversia de Itaipú, la "diplomacia militar" entre ambos países pareció más una comunicación diplomática abierta. Una gran parte de la opinión militar en ambos países favoreció con éxito la alternativa de mantener canales abiertos antes que adoptar una postura beligerante. Un tácito acuerdo evitó una carrera armamentis- 
ta, aun cuandó los gastos militares argentinos crecieron a paso rápido.

Varias actitudes militantes argentinas durante el régimen militar hicieron más difícil que Brasil quisiera, con su apertura bajo Figueiredo, cooperar más estrechamente en intercambio militar; una extensión del asunto concerniente a la lucha anticomunista y la cooperación subregional contra los "subversivos", las tensiones chileno-argentinas, intervención en el golpe de 1980 en Bolivia, ayuda clandestina de seguridad en América Central, la "guerra sucia" contra los izquierdistas y la campaña de las Malvinas. Incluso en un ejercicio conjunto, como lo fueron las maniobras navales anuales "Fraterno", no se efectuó una alianza. Han sido más o mènos frecuentes las visitas militares con intercambios de opiniones, pero los acuerdos de entrenamiento en el otro país a más largo plazo, son escasos. Las fuerzas navales y aéreas argentinas han adquirido aviones bombarderos de ataque a tierra construidos en Brasil, el Xavante-EMB-326. Brasil está dispuesto a vender más armas a Argentina, pero tiene menor oportunidad de usar armamento producido en Argentina, porque prefiere desarrollar sus propias armas a través de su propia e importante industria de defensa.

Las instituciones tanto militares como de seguridad están reevaluando sus autoimágenes y misiones de seguridad con el retorno del gobierno civil. Los niveles de tensión en cuanto a la seguridad del Cono Sur han disminuido considerablemente desde 1978-82, de manera que esta redefinición será un proceso que durará varios años y dependerá de la evolución de su política interna así como la de los países vecinos. Las instituciones militares y de seguridad de Brasil y de Argentina buscarán nuevas doctrinas y modelos a medida que se profesionalicen y, con la intensificación de la cooperación, pueden incluso estar dispuestas a iniciar un diálogo mutuo que sea más sustancial.

A medida que pasen los años, ambos países poseerán armamento más sofisticado, con producción interna más avanzada (entre los líderes del Tercer Mundo) y mayor capacidad internacional. Argentina ya se ha rearmado, al menos a los niveles pre-Malvinas, pero aún permanece baja en capacidad de despliegue y niveles de alerta. Brasil puede desarrollar una rápida fuerza de despliegue a sus áreas fronterizas. Pero debido a asuntos de seguridad anteriores, que estaban mayormente orientados al interior y la visión Este-Oeste impartida por la doctrina norteamericana, las ideas para evitar la guerra internacional en América del Sur han sido poco desarrolladas, aún después del conflicto de las Malvinas. "Salir del paso a tontas y a locas" o negociar tácitamente ya no basta, especialmente desde el momento que es cada vez menos probable, y Estados Unidos ha 
demostrado ser menos capaz de ejercer una influencia restrictiva ${ }^{11}$. Del mismo modo, cada país desarroliará su propia doctrina de seguridad y perseguirá sus propias opciones, más libres de la influencia norteamericana que en el pasado, mejor informados por teóricos preparados nacionales y continentales, y menos involucrados en asuntos Este-Oeste.

\section{El asunto nuclear}

Una carrera tácita y preocupante de desarrollo de la tecnología nuclear puede precipitar inadvertidamente una carrera de armas nucleares, ya sea en el caso de una crisis o por afán de conseguir status como incentivos para cruzar el umbral. Ambos países persiguen políticas que mantienen abiertas sus opciones para construir un dispositivo nuclear mientras que niegan apasionadamente cualquier intención de hacerlo. Argentina está más avanzada en la tecnología y la capacidad nuclear, y esto es motivo de orgullo nacional y una medida de haber alcanzado con éxito una madurez cientifica. De modo que Argentina es el que da mayor velocidad al factor "impulso" en el tira y afloja del escalamiento o la inadvertida tendencia hacia el umbral nuclear, resultante de ló dos programas civiles. EI hecho que ambos programas sean función del desarrollo cientifico-tecnológico más que de un afán por armas no excluye las implicancias que esto tiene para la seguridad.

Dado que la tecnología nuclear constituye una de las pocas áreas de superioridad argentina sobre Brasil, y porque tiene aplicaciones de prestigio y comerciales, Argentina no permitirá quedarse atrás. Si Argentina llegara a producir plutonio para uso en armamento o anunciara su capacidad para construir un aparato explosivo en un futuro cercano, Brasil casi inevitablemente le seguirá los pasos. El empeoramiento de este dilema.inminente puede constituir el legado más negativo de la Guerra de las Malvinas y factores tales como el orgullo nacional y científico, y las relaciones Norte-Sur hacen que sea uno de los más difíciles de resolver.

Ha habido un grado limitado de cooperación en usos pacíficos de energía nuclear, por medio de diversos tratados que dieron a los brasileños la sensación que ellos tenían también una parte del status obtenido con el progreso nuclear argentino. El anuncio sorpresivo por parte de Argentina en noviembre de 1983 de que habían logrado desarrollar la tecnologia para el enriquecimiento del uranio por medio de un programa secreto, y que iban a proceder a

프 En cuanto a la necesidad de aplicar medidas para crear mayor seguridad en Sudamérica ahora, ver Alexandre de S. C. Barros, "Confidence Building and Mutual Trust". Trabajo presentado ante la 25a Reunión Anual de la Asociación de Estudios Internacionales, Atlanta, Georgia, en marzo 27-3I, de 1984, especialmente las páginas 11-18. 
construir una planta productora, conmocionó a los brasileños e introdujo un grado aún mayor de suspicacia y desconfianza en las relaciones, y frenó también la cooperación en el campo de la ciencia nuclear.

En retrospectiva, el tratado de cooperación nuclear de 1980, firmado después que la administración antiproliferación de Carter, probablemente sirvió más como una notificación pública de que ambos países no eran rivales en el campo nuclear, que como indicador de estrecha colaboración futura.

Argentina tiene sus propias minas de uranio y está bastante adelantada en la senda de dominar el ciclo completo del combustible nuclear. Brasil podría estar en condiciones similares en la década de los años 90. Desde el punto de vista del control de armas, el problema político se transforma en el del manejo de la casi capacidad de producir armamento nuclear por medio de la creación de un ambiente de mayor confianza y sistemas de salvaguarda regional, sin que se llegue a precipitar el momento en que cualquiera de los dos decida construir una bomba. Esta situación de "pre-disuasión" será difícil de manejar, dadas las características regionales de inseguridad política, y seguirá existiendo, ya sea bajo gobiernos civiles o militares.

\section{Perspectivas DE SEgURTDAD FUTURA}

Condiciones de seguridad a corto plazo (1985-86)

El aspecto de seguridad en la relación tendrá mayor significación a medida que transcurre el tiempo. Existe una "ventana de oportunidad" para que durante este tiempo se apliquen medidas para fomentar la creación de un ambiente de mayor seguridad mutua en las áreas de desarrollo tanto convencional como nuclear, para disminuir la probabilidad de que se produzca la reasersión de asuntos problemáticos territoriales o geopolíticas, y el inicio de una carrera armamentista convencional o nuclear. Argentina continúa insegura o desconfiada con respecto a las intenciones de Brasil en cuanto al Continente. Las primeras iniciativas puede que dependan de Brasil, a medida que su institución de seguridad, incluyendo el Servicio Nacional de Inteligencia (SNI), adopta una postura más orientada hacia el exterior o bien hacia la "defensa nacional". Si las medidas para establecer un clima de confianza y para el manejo de las tensiones no se toman ahora, una serie de acontecimientos que probablemente se verán a mediano plazo, podrían dar comienzo nuevamente a intensos antagonismos que no sólo amenazarían toda la relación de cooperación sino que también escalarían el conflicto a límites nunca vistos. No obstante, dado el rol desempeñado recientemente por los militares argentinos y la percepción que en 
Brasil se tiene de ellos en el sentido que son impredecibles, es poco probable que se establezca una estrecha cooperación en el campo de la seguridad durante el corto plazo. Habrá una tendencia a tratar de igualar al otro en el desarrollo de armamento de producción nacional, con mayor énfasis en ítemes de tecnología más avanzada como el sea-skimmer y misiles balísticos, así como sistemas de defensa de navios.

La influencia militar en la formulación de la política exterior se verá reducida, de manera que necesitará del liderazgo civil para fomentar la détente. A medida que el gasto militar argentino se vaya reduciendo considerablemente, el brasileño se verá ligeramente aumentado durante este periodo. Ambos lados tratarán de alcanzar niveles más altos de autosuficiencia. Brasil no tiene intención de convertirse en potencia militar de categoría mundial. Sus fuerzas militares aún están desplegadas para fines domésticos. Una reorientación hacia el despliegue para la defensa externa requeriría de niveles de gasto que es poco probable que se le concedan. Las fuerzas argentinas ya hicieron una demostración internacional que basta y sobra para las hostilidades locales, pero que al mismo tiempo demostró un nivel de capacidad insuficiente para lograr una victoria contra una potencia de mayor envergadura ubicada lejos de su propio territorio.

E1 solo crecimiento de la industria de armas de Brasil, vigorosamente orientada hacia la exportación, y su programa especial, incentivado por una economía más grande y dinámica, así como el aumento gradual planificado de tamaño de las fuerzas armadas, hará que con el transcurso del tiempo sobrepase con creces la capacidad de Argentina de mantener la "paridad" convencional por medio del énfasis en calidad y entrenamiento. Este gran desequilibrio futuro, y un probable afán argentino de "transformarse en nuclear" para poder compensar, constituye la más seria amenaza probable en el futuro de América Latina. Las medidas de carácter político que se tomen para fomentar un clima de confianza deberian ponerse en funcionamiento antes que se haga aparente para ambos gobiernos la capacidad de Brasil de establecer una arrasante hegemonfa.

\section{Condiciones de seguridad en el mediano plazo (1987-89)}

Los problemas principales en este plazo podrían consistir en:

I. Grave preocupación argentina ante un Brasil mucho más poderoso que está expandiendo su influencia en el Continente y aventajándola militar y económicamente.

2. La introducción de un factor status dentro de la ecuación armas nucleares. 
Wayne A. Selcher / Relaciones entre Brasil y Argentina en la década del $80 \ldots$

3. Reafirmación de una postura internacionalmente agresiva por parte de los militares argentinos.

4. Colapso económico o político grave en cualquiera de los dos países.

En la actualidä, estas condiciones son poco probables y es más posible que Argentina y no Brasil dé Iugar a tal inestabilidad. Las características del mediano plazo dependerán de la calidad de la relación política y del éxito que tengan las medidas que para aumentar la confianza se tomen en el corto plazo. Las siguientes son las posibles tendencias en cuanto a seguridad que podrían fortalecer Ios lazos de unión y aquellas que podrían debilitarlos, ordenados de mayor a menor dentro de un margen de importancia.

\section{TENDENCIAS PROBABLES DE SEGURIDAD QUE FORTALEGERAN LOS LAZOS}

\section{Ma yor Impacto}

1. Programas conjuntos de entrenamiento militar e intercambio de puntos de vista y de doctrina.

2. Resolución aceptable de las condiciones del pago de la deuda que contribuya a la estabilidad política de ambas partes.

3. Compatibilidad entre los regímenes políticos, especialmente de gobierno civil.

4. Menor énfasis por parte de militares argentinos en modelos geopolíticos.

5. Ejercicios militares conjuntos que impliquen compartir más que en el presente.

6. Producción conjunta de armas.

7. Solución de las disputas fronterizas argentinas con Chile y las Malvinas.

8. Lograr un acuerdo en control de armas convencionales.

9. Ayuda conjunta o paralela en asuntos de seguridad a vecinos en el Cono Sur.

10. Cooperación nuclear, salvaguardas, y ratificación bipartita de un acuerdo regional o subregional de no-proliferación.

$$
\text { Menor Impacto }
$$

1. Cooperación en la exploración antártica. 
2. Transición política calmada en Paraguay.

3. Concesión de utilización portuaria por parte de Chile a Bolivia.

4. "Desmilitarización" del Atlántico Sur.

TENDENCIAS PROBABLES DE SEGURIDAD QUE DEBILITARIAN LOS LAZOS

\section{Ma yor Impacto}

1. Percepción mutua de que el otro ha logrado alcanzar un nivel cercano a la producción de armas nucleares.

2. Aumento de la capacidad de producir armas en un Brasil poderoso y autónomo y que incluiría cohetería y misiles guíados de largo alcance.

3. Una crisis de la deuda que afecte la estabilidad política de cualquiera de los dos pafses, pero especialmente de Argentina.

4. Incompatibilidad de regímenes.

5. Rearme sostenido argentino que sobrepase los niveles alcanzados en 1982.

6. Adquisición o construcción por parte de cualquiera de los dos países de un submarino nuclear.

7. Enfrentamiento armado de Argentina con Ghile o con Gran Bretaña.

8. Aumento notable de la influencia militar brasileña (mayor que la argentina) en Bolivia, Paraguay y Uruguay, especialmente si se extiende hasta afectar los sistemas políticos.

9. Surgimiento de la capacidad y deseo del Brasil de proyectar poderío militar hacia el exterior. cino.

10. Intervención militar de cualquiera de los dos a un país ve-

$$
\text { Menor impacto }
$$

1. Acuerdos nuevos o mejores en cuanto a la seguridad de Brasil con Estados Unidos o Chile.

2. Aguda rivalidad entre los dos países en la venta de armas en Sudamérica.

3. Agudos desacuerdos en exigencias conflictivas respecto de la Antártica. Sur.

4. Establecimiento de una base naval brasileña en el Atlántico 
Wayne A. Selcher / Relaciones entre Brasil y Árgentina en la década del $80 \ldots$

\section{CONGLUSIONES}

\section{EL ESPEGTRO DE LAS RELAGIONES}

El rango de posibilidades presentes y futuras en la calidad de las relaciones brasileño-argentinas se puede expresar en la siguiente escala que va desde relaciones "buenas" o esencialmente cooperativas, a través de un punto medio de cooperación mezclada con desacuerdo, hasta un estado de relaciones "forzadas" o conflictivas en alto grado. (Una sexta posibilidad, la de evitarse mutuamente, ya no es viable dados los intereses que cada uno tiene involucrados en la relación).

\begin{tabular}{lllll}
$\begin{array}{l}\text { Integración } \\
\text { Económica }\end{array}$ & $\begin{array}{l}\text { Interdependencia } \\
\text { Económica }\end{array}$ & $\begin{array}{l}\text { Competencia } \\
\text { Amistosa }\end{array}$ & $\begin{array}{l}\text { Cauta } \\
\text { Rivalidad }\end{array}$ & $\begin{array}{l}\text { Tensa } \\
\text { Hostilidad }\end{array}$ \\
\hline Cooperación & & & Conflicto
\end{tabular}

"Buenas Relaciones"

"Relaciones Forzadas"

El estado actual de las rivalidades puede ser definido como de "competencia amistosa", con una clara inclinación neta hacia el lado de la cooperación del punto medio del espectro. Los gobiernos y los públicos educados de ambos países están conscientes de las rivalidades y resentimientos del pasado, ya fueran reales o imaginarios, pero han llegado a la conclusión de que existen suficientes intereses comunes para crear un espiritu y un marco de cooperación que puede sobrepasar los desacuerdos ocasionales. La competencia se mantiene más bien implícita, especialmente para los sectores más jóvenes de liderazgo público y privado.

Si la cooperación se extendiera hacia áreas clave de la vida económica de ambos países, podría sobrevenir la interdependencia económica. Esta situación estaría caracterizada por medidas tales como importantes proyectos conjuntos de investigación y desarrollo, aumento significativo del comercio bilateral expresado en porcentaje del comercio total, y aumento del flujo de personas e información entre los dos países. Un grado limitado de cooperación en el campo de la ciencia nuclear podría desarrollarse en este ambiente. Tendrían que ser creados mecanismos institucionales útiles para el manejo de las disputas que resultarían de una interacción más intensa, especialmente si se tiene en cuenta la mayor y probablemente creciente ventaja comparativa de Brasil. Este grado de ventaja sigue siendo el mayor, pero no el único obstáculo a tal grado de cooperación. El grado de cooperación más intenso sería aquel 
de integración económica, un proceso para eliminar barreras comerciales y llevar a cabo actividades como sustitución conjunta de importaciones, fondo común del mercado e implementación de políticas conjuntas con respecto a terceros y en asuntos multilaterales.

Si sucediera lo contrario y la relación se viera forzada, podría reaparecer un período, como el de principios de la década del 70, de cauta rivalidad. Esto se caracterizaría por campañas publicitarias negativas, el resurgimiento de los ya aplacados estereotipos negativos, la atribución de motivaciones ocultas al otro lado, un agudizamiento de preocupaciones respecto de la mutua seguridad, competencia abierta y oculta en pos de esferas de influencia, y niveles de cooperación económica muy reducidos. Un deterioro aún mayor daría lugar a una tensa hostilidad, caracterizada por el alerta militar en áreas fronterizas, vigilancia mutua, niveles más altos de gastos de defensa, con enfoque en las actividades de inteligencia del otro y aumento de los niveles de tensión en todo el Cono Sur.

\section{ProbabILIDADES RELATIVAS EN EL GORTO Y MEDIANO PLAZO}

El corto plazo (1985-86)

La más alta probabilidad para el corto plazo es la continuación de una competencia amistosa que se inclina levemente hacia la interdependencia económica. Es poco probable que se logre una real interdependencia, ya que requeriría que se contara con más tiempo y que se efectuara una diligente búsqueda y seguimiento de las complementaridades. La integración económica, en el mejor de los casos, necesitaría de varios años de incremento del nivel de confianza y de estabilidad con niveles de atención mucho más altos y mayor sensibilidad mutua, para lo que no se menciona siquiera el hecho que tal grado de cooperación no tiene precedentes en Sudamérica. Por otra parte, los indicadores a corto plazo no indican que vaya a haber un deterioro, ya sea hacia el resurgimiento de una cauta rivalidad o un escalamiento hacia una tensa hostilidad. Un ordenamiento especulativo de las probabilidades a corto plazo, sería:

Competencia amistosa

Interdependencia económica

Cauta rivalidad

Integración económica

Tensa hostilidad
$75 \%$ (a grandes rasgos $80 \%$ cooperativo, $20 \%$ competitivo)

$10 \%$

$10 \%$

menos de $5 \%$

menos de $5 \%$ 
Wayne A. Selcher / Relaciones entre Brasil y Argentina en la década del $80 \ldots$

\section{El mediano plazo (1987-89)}

Después de 1986, la calidad de las relaciones dependerá en mayor medida del grado de beneficio económico que ambos países hayan logrado en el corto plazo. Los factores formativos de importancia incluirán las condiciones de pago de la deuda externa, salud de la economía, viabilidad del comercio de compensación, grado de orientación interna o externa, estabilidad interna, compatibilidad del régimen, modificación de la ventaja económica comparativa, status político de los estados vecinos, y status de los programas de desarrollo nuclear. Para fines hipotéticos, los acontecimientos podrían describirse en los siguientes tres escenarios, cada uno con sus circunstancias formativas y probabilidad especulativa.

Escenario I: Gontinuación de un tono esencialmente cooperativo con discreta competenc:a ( $65 \%$ de probabilidad). Alentado en gran medida por el establecimiento de medidas confiables de resolución de conflicto y ambiente de confianza, compatibilidad de régimen, reanudación del proceso de crecimiento económico, alivio en el pago de la deuda, y suficientes retribuciones a corto plazo para mantener ambas partes interesadas.

Escenario 2: Surgimiento de la cautela, inclinándose hacia la hostilidad ( $25 \%$ de probabilidad). Posiblemente producido por una mayor amenaza a la relación, manejo deficiente de los peligros de la carrera de armas pre-nuclear o pre-disuasión, que todavía no han sido resueltos. A medida que transcurre la década, la probabilidad que este escenario se haga realidad aumentará si se continúa por la senda de no prestarle atención a este asunto.

Escenario 3: Aceleración del proceso de cooperación hacia una integración económica (10\% de probabilidad). Ello implicaría un cambio radical juzgado poco probable en vista de los obstáculos que plantean la inestabilidad política, niveles insuficientes de complementariedad económica, preferencia por la acción individual y la atención, por lo general mayor, que se le da a otros socios.

Con la disminución de la preponderancia de Norteamérica en América del Sur, Ios roles de Argentina y Brasil cobrarán mayor importancia relativa dentro de un sistema más autónomo de manejo de asuntos continentales. La calidad de su relación será uno de los factores que en gran medida establezcan el tono de la política internacional de Sudamérica. Si se maneja en forma apropiada, el espíritu ahora aparente de cooperación bilateral conlleva la posibilidad de alejar al Continente de una senda de conflicto en politica internacional que parecía tan probable al iniciarse esta década y acercarlo hacia relaciones mutuas de mayor beneficio. 